Artículo de reflexión

Apuntes del CENES

ISSN 0120-3053

Volumen $33-\mathrm{N}^{\circ} .58$

Julio - Diciembre de 2014

Págs. 83-108

\title{
Equidad y ética en el recaudo tributario colombiano: 1990-2010
}

\author{
Equity and ethics in the Colombian \\ tax collection: 1990-2010
}

Héctor Fernando López Acero* Mónica Shirley Chaparro Parra**

Fecha de recepción: 25 de abril de 2014

Concepto de evaluación: 6 de mayo de 2014

Fecha de aprobación: 15 de septiembre de 2014

* PhD. Filosofía Universidad de Valencia, España. Economista y magíster en Economía, Universidad Nacional de Colombia. Profesor Escuela de Economía y Administración, Universidad Industrial de Santander, Bucaramanga, Colombia. hecferlopez@hotmail.com

** Economista de la Universidad Industrial de Santander, Bucaramanga, Colombia. monichaparro_91@hotmail.com 


\section{Resumen}

El presente artículo pretende analizar la problemática de inequidad en el sistema impositivo colombiano, particularmente de los años 1990-2010, a la luz de unos determinantes éticos heredados a partir del proceso de colonización española. Aunque la Constitución Política manifiesta el principio de equidad tributaria, lo cierto es que las reformas fiscales realizadas a partir de la década de los noventa han conducido a hacer el sistema impositivo aún más inequitativo. Frente a ello cabría indagar si el problema está más asociado a inconvenientes de tipo administrativo y técnico, o si el complejo ético característico del colombiano determina de manera importante el desarrollo dado al tema fiscal.

Palabras clave: recaudo tributario, imposición fiscal, impuestos directos, impuestos indirectos, equidad, ética, Estado.

JEL: A12, E62, H20.

\section{Abstract}

This article aims to analyze the problematic of inequity in the Colombian tax system, particularly of the years 1990-2010, from ethical determinants inherited from the process of Spanish colonization. Although the Political Constitution expresses the principle of tax equity, the truth is that the tax reforms carried out since the 1990s have led to even more inequitable tax system. In response we could find out if the problem is more associated with disadvantages of administrative and technical type, or if the ethical complex typical of the Colombian significantly determines the development given to the fiscal issue.

Keywords: tax collection, fiscal contribution, direct taxes, indirect taxes, equity, ethics, State. 


\section{INTRODUCCIÓN}

Una de las grandes funciones que cumple el Estado a través de la política fiscal, es la redistribución del ingreso que, en últimas, debiera desembocar en una mejora social de quienes se encuentran bajo difíciles condiciones económicas. Desde la perspectiva del recaudo fiscal, la forma como se legisla, quién, cómo y cuánto debe contribuir cada individuo al presupuesto nacional, genera unos cambios en la capacidad adquisitiva en tanto el Estado capta cierta proporción de sus ingresos monetarios. En este sentido, los impuestos pueden ser de dos tipos: directos e indirectos. Del primero, su principal fuente de entrada al fisco nacional es el impuesto a la renta, y del segundo, el impuesto al valor agregado (IVA). Asimismo, para lograr una equidad en términos tributarios se requiere enfáticamente que los impuestos directos tengan una mayor preponderancia sobre los indirectos, en la medida en que estos últimos no discriminan según la capacidad de pago del contribuyente sino que, por el contrario, conceden un trato igualitario.

En el caso colombiano, aunque algunas de las diez reformas tributarias determinadas en la última década del siglo XX y primera del XXI, establecieron dentro de sus objetivos promover la equidad y la eficiencia fiscal, esto no solo ha sido imposible de materializarse sino que, además, y como consecuencia, se ha terminado sobrecargando el peso de la tributación en los hombros de quienes menos tienen capacidad de soportarlo. Incluso, con el proceso de apertura económica de los años noventa se inicia una serie de reformas que propugnaron el aumento del IVA y ciertas exoneraciones del pago de impuesto a la renta. Así, por ejemplo, los recaudos del impuesto a la renta como 
porcentaje del PIB disminuyeron de $5,4 \%$ en 1991 , a $4,9 \%$ en 1997 , mientras el del IVA ascendió de $2,4 \%$ a 3,6 \% en el mismo periodo (Arévalo \& Rodríguez, 2001).

Intentar comprender el trasfondo de esta situación, es decir, los determinantes últimos de que no haya sido posible ejecutar un recaudo que propenda a la equidad, implica necesariamente prescindir de las causas que se le otorgan comúnmente, pero que de ninguna manera se aproximan a una reflexión honda sobre el problema en cuestión. De modo que si este se le atribuye a estrategias técnico-instrumentales, argumentando que han resultado significativamente inoperantes, no podría construirse una visión completa y acabada de lo que hay detrás de esta situación del fisco nacional.

En tal estado de cosas, se evidencia la relevancia de analizar la dinámica del recaudo fiscal que caracterizó al país durante el periodo 1990-2010, a la luz de los condicionantes éticos nacionales heredados desde la colonia, en medio de los cuales tiene lugar la interacción entre las esferas social, económica y política. Y es precisamente esta deformación ética de la sociedad colombiana, caracterizada, entre otras cosas, por la irresponsabilidad y el ansia de dinero a cualquier costo, la que funciona como una enorme roca que obstaculiza de manera importante el positivo devenir de la política tributaria. Quizá sea justamente en la problemática nacional de inequidad en el recaudo fiscal donde se pone de manifiesto de forma mu- cho más nítida la trascendencia de estas particulares pautas de comportamiento.

El presente artículo contiene fundamentalmente tres apartados que son un intento por desarrollar estos planteamientos. El primero contiene un marco teórico del Estado: su origen, su monopolio fiscal y una crítica a los postulados de la economía clásica. El segundo realiza un análisis de las diversas reformas tributarias desarrolladas a lo largo de las dos décadas investigadas, y determina qué tanta relación guardaron con el principio de equidad en el recaudo fiscal. El tercero incorpora un remonte al pasado histórico colombiano, desde la época de la colonia, para encontrar los principales determinantes a partir de los cuales se instauró la ética nacional que aún hoy se hace manifiesta con imperante fuerza. En cuanto a lo último, se abriga la ilusión de que pueda ser de algún aporte a la comprensión de la problemática que es objeto de estudio en el presente artículo.

\section{EL ESTADO Y LA TRIBUTACIÓN}

La dirección del recaudo tributario se encuentra en manos de un ente específico: el Estado. De modo que si la intención es estudiar a fondo una problemática de tipo fiscal, nada ha de lograrse si se da por hecho esta funcionalidad estatal, dejando atrás la posibilidad de reconocer la complejidad albergada por este ente que, lejos de ser uno cualquiera, es, justamente, aquel que tiene la facultad de interferir en la vida de todos los hombres. Habrá que preguntarse por el origen del Estado 
moderno, esto es, por su fundamento. Thomas Hobbes detiene su mirada en el ser humano y reconoce que todos nacen iguales: cada uno hace alarde de sus propios talentos, pero menosprecia los de los demás. Ello permite reconocer la tendencia natural del hombre a diferenciar según las categorías amigo-enemigo.

$\mathrm{Si}$, adicionalmente, existe una limitación en la cantidad de recursos disponibles, como efectivamente ocurre, lo que queda es un enfrentamiento por obtener lo deseado. Ello sugiere que es la guerra y no la paz, la condición innata al ser humano. No obstante, al hombre lo inquieta en todo momento un anhelo: el de vivir tanto tiempo como la naturaleza lo permita. Siendo dos los instintos primarios del hombre: el cuidado de sí mismo y el actuar violento, no parece haber quedado más alternativa que la de la creación del Estado, esto es, la de reducir todas las voluntades a una sola voluntad. El Estado es, entonces, según Hobbes (1994):

Una persona de cuyos actos, por mutuo acuerdo entre la multitud, cada componente de ésta se hace responsable, a fin de que dicha persona pueda utilizar los medios y la fuerza particular de cada uno como mejor le parezca, para lograr la paz y la seguridad de todos. (p.145)

Si el fundamento del Estado es la violencia, resulta apenas consecuente que este deba disponer del monopolio de la fuerza que, por lo demás, no tendría cabida de no ser porque dispone del monopolio fiscal.
Son entonces los individuos, quienes, al desear que el Estado patentice un bienestar colectivo, financian, es decir, sostienen la existencia estatal. Esto significa que el poder del Estado alcanza dimensiones inconmensurables y aun así hay algo más trascendental: "Los Estados presentan una apariencia caótica, irracional, con múltiples autonomías ministeriales, presionadas de forma errática e intermitente por los capitalistas, pero también por otros grupos de poder" (Mann, 1997, p.82).

Ni en su origen ni en su desarrollo, el Estado se ha mostrado como manifestación de una racionalidad propiamente dicha. Al Estado cabría otorgarle un significativo grado de arbitrariedad. En este sentido, no puede proclamarse con seguridad que las decisiones tomadas con respecto al tema tributario, que lleva inmerso un importante proceso de redistribución de los recursos, obedezca a unos estrictos cálculos macroeconómicos, sino que hay algo de fondo que determina más trascendentalmente el rumbo que tome esta política: la siempre problemática y compleja superposición de intereses políticos, sociales y económicos que se mueven en el interior del Estado.

Hay un interés particular y singular que tiende a salir victorioso en el tema tributario: el del capital, el de esa relación social de poder, como magistralmente lo conceptualizara Marx. Específicamente para el caso colombiano, el argumento estatal del estímulo a la inversión por medio de exenciones tributarias cae por su 
propio peso, pues la realidad expresa que la atenuación de las cargas impositivas al capital no se traduce necesariamente en mayores oportunidades de empleo e ingreso para el conjunto de la sociedad, sino que el resultado es un ensanchamiento de los bolsillos de unos pocos. Sin embargo, acá hay algo que resulta sumamente curioso: la teoría económica clásica proclama la no intervención del Estado en los asuntos que atañen a lo económico, por obstaculizar el libre suceder de las fuerzas económicas, al mismo tiempo que busca un favorecimiento al capital por parte del Estado.

Uno de los postulados de la teoría clásica, quizá uno de los más trascendentales, reza: la interferencia gubernamental caracterizada, entre otras cosas, por ser nociva e imprudente, no debe más que mantenerse al margen de los asuntos económicos, pues todo se encamina hacia un equilibrio económico que solventa cualquier eventualidad. El economista William Petty tuvo la fortuna de encontrarse dentro de un periodo previo al dogmatismo económico, y ello le permitió, nada más y nada menos, concebir el tema tributario bajo la mirada de la realidad y no de la idealidad. Así, Petty (1986) puede reconocer, por ejemplo, que el recaudo de impuestos tiende a disminuir en el caso en que la población suponga que el Estado malgasta esos ingresos recibidos o que la cuantía de los pagos es impuesta de un modo desigual. Además de mencionar como obstáculos al adecuado desarrollo del ejercicio tributario, el permanente enigma de cuál debiera ser efectivamente la magnitud de la imposición determinada desde el Estado y la creencia en que el dirigente político transfiere parte del dinero recaudado a ciertas personas de su favoritismo.

Pero Petty no se limitó a simplificar lo fiscal a unas explicaciones meramente económicas, sino que su interés trascendió: intentó capturar la complejidad misma bajo la cual gravita el tema del recaudo tributario. Posteriormente, el pensador económico Adam Smith, aunque menciona en su investigación de la riqueza de las naciones lo fundamental de ejecutar el principio de equidad tributaria a fin de conservar el orden social, sostiene que el liberalismo económico necesariamente debe quedar exento de toda interferencia gubernamental, pues ni aun el gobierno más previsor y prudente puede hacer tanto bien a la sociedad como la iniciativa del interés individual. Es ese interés de los hombres de negocios el que, según Smith, tiene la posibilidad de conducir al bienestar colectivo. Pero basta detenerse un instante y contemplar el mundo para darse cuenta que ese postulado no es más que una conjetura, una simplicidad, una hipótesis incompleta que oculta el verdadero escenario del mundo.

Clara y contundentemente lo expresaría Keynes (1943), quien tal vez sea el único economista que pudo ver con claridad el contexto fáctico de lo económico: “... las características del caso especial supuesto por la teoría clásica no son las de la sociedad económica en que hoy vivimos, razón por la que sus enseñanzas engañan 
y son desastrosas si intentamos aplicarlas a hechos reales" (p. 15). Si la teoría clásica se refiere a un mundo que tiene la particularidad de no-ser, cabría dudar de la utilidad práctica que de sus postulados pudiera emerger para la sociedad.

No obstante, para el caso colombiano, en la década de los ochenta, y más intensamente en la de los noventa, cobraron vigor los imperativos económicos de crecimiento económico y la idea de que las fallas ocasionadas por la intervención estatal eran de mayores dimensiones que las presentadas por las fallas de mercado, es decir, lo que primó fue la interiorización de unos principios de idealización y perfección económica. Bajo tal estado de cosas, problemas como la desigualdad en la distribución del ingreso, que debiera atenderse desde la tributación misma por medio de un sistema impositivo progresivo, no ha reclamado, bajo la estructura neoliberal, la debida importancia. La teoría clásica expresaría sin lugar a dudas: la situación a la que llevan las fuerzas económicas es la mejor posible y nada mejor se lograría si el Estado interviniera.

Esto ha llegado a tal punto que la búsqueda de equidad fiscal se toma por causante de distorsiones, en la medida en que altera las decisiones de inversión, al mismo tiempo que se le acusa de facilitar la evasión al tener que extenderse el número de tasas marginales. Para, en último término, sentar una defensa de la política fiscal caracterizada por una estructura tributaria óptima, esto es, que sea de fácil administración. Frente a ello lo que queda es un mar de interrogantes. No parece ser que una política fiscal con estas cualidades tenga la robustez suficiente para atender las particulares problemáticas colombianas: el debilitamiento del país bajo una de las mayores tasas de inequidad en el mundo. Y, entonces, miente la economía y miente el Estado: la primera prometiendo un bienestar general y el segundo manifestando en el pacto social un compromiso con la equidad vía impuestos, que por ningún lado se materializa. Es así como se hace patente la crisis.

\section{EQUIDAD Y RECAUDO TRIBUTA- RIO COLOMBIANO}

La Constitución Política de 1991 expresa en el artículo 363: "El sistema tributario se funda en los principios de equidad, eficiencia y progresividad. Las leyes tributarias no se aplicarán con retroactividad". No obstante, las políticas tributarias que se han llevado a cabo en el país a lo largo de las dos décadas de estudio no se han correspondido con lo planteado en el pacto social que se hace llamar Constitución. El paisaje real se encuentra bastante distanciado de ese ideal tributario, tanto así que, por el lado de la equidad del sistema, los analistas del fisco colombiano encuentran que las reformas que se hicieron a partir de la década de los noventa han conducido a hacerlo más inequitativo (Arévalo \& Rodríguez, 2001). El panorama ha sido, entonces, el de un sistema nacional de recaudo donde prevalecen los impuestos de tipo indirecto sobre los de tipo directo (Ver tabla 1). 
Tabla 1. Ingresos fiscales directos e indirectos. Cifras en millones de pesos corrientes.

\begin{tabular}{|r|r|r|r|}
\hline AÑOS & \multicolumn{1}{|c|}{$\begin{array}{c}\text { Ingresos } \\
\text { tributarios } \\
\text { directos }\end{array}$} & $\begin{array}{c}\text { Ingresos } \\
\text { tributarios } \\
\text { indirectos }\end{array}$ & $\begin{array}{c}\text { Total ingresos } \\
\text { tributarios }\end{array}$ \\
\hline $\mathbf{1 9 9 0}$ & 822.513 & 1.150 .419 & 1.972 .932 \\
\hline $\mathbf{1 9 9 2}$ & 1.846 .321 & 1.747 .242 & 3.593 .563 \\
\hline $\mathbf{1 9 9 4}$ & 2.810 .450 & 3.764 .009 & 6.574 .459 \\
\hline $\mathbf{1 9 9 6}$ & 4.046 .703 & 6.086 .561 & 10.133 .264 \\
\hline $\mathbf{1 9 9 8}$ & 6.061 .012 & 8.948 .288 & 15.009 .300 \\
\hline $\mathbf{2 0 0 0}$ & 7.526 .964 & 11.734 .106 & 19.261 .070 \\
\hline $\mathbf{2 0 0 2}$ & 12.110 .715 & 15.429 .100 & 27.539 .815 \\
\hline $\mathbf{2 0 0 4}$ & 16.409 .346 & 21.367 .234 & 37.776 .580 \\
\hline $\mathbf{2 0 0 6}$ & 22.955 .347 & 29.849 .358 & 52.804 .705 \\
\hline $\mathbf{2 0 0 8}$ & 29.987 .756 & 37.008 .854 & 66.996 .610 \\
\hline $\mathbf{2 0 1 0}$ & 30.350 .812 & 39.809 .514 & 70.160 .327 \\
\hline
\end{tabular}

Fuente: cálculos de los autores con base en cifras de la DIAN.

Se dimensionan las consecuencias de que las reformas tributarias colombianas realizadas en las dos décadas pasadas no se hayan caracterizado por su afán de contribuir a menguar la crónica situación de inequidad nacional, cuando se reconoce que el índice de Gini ${ }^{1}$ colombiano, según cifras del Banco Mundial, pasó de 0,51 en el año 1991 a 0,56 para el 2010. Frente a esto, la teoría económica ortodoxa reza que la equidad viene a estar dada por los resultados distributivos que traen consigo las fuerzas del mercado y, siendo así las cosas, la atención debe dirigirse fundamentalmente a la eficiencia en la gestión del recaudo. Sin embargo, esto habría que ponerlo en tela de juicio, pues es apenas comprensible que un país como Colombia, que no sobresale precisamente por sus favorables condiciones de justicia y equidad ${ }^{2}$, deba verse en la obligación de utilizar la tributación con fines además redistributivos, actuando a favor de la progresividad en los impuestos, es decir, imponiendo iguales obligaciones tributarias a personas con igual capacidad de pago y mayores tributos a aquellos ciudadanos que tienen una mejor dotación de factores.

El comparativo internacional ofrece la posibilidad de visualizar la magnitud de la problemática en estudio. En términos generales, puede decirse que el sistema impositivo latinoamericano se caracteriza

El índice de Gini mide hasta qué punto la distribución de ingreso de los individuos dentro de una economía, en este caso la economía de Colombia, se aleja de una distribución perfectamente equitativa. Un índice de Gini de cero representa equidad absoluta, mientras que un índice de Gini de 1, representa total inequidad.

2 Según la Encuesta de Calidad de Vida del DANE, en el año 2008 el índice de Gini para Colombia llegó a ser de 0,59, uno de los más altos del mundo. El $10 \%$ más rico de la población tenía en sus manos la mitad del PIB, mientras el $10 \%$ más pobre únicamente contó con el $0,6 \%$ de este. Adicionalmente, según cifras de la ONU, el $27,7 \%$ de la población nacional presenta necesidades básicas insatisfechas. Más del $40 \%$ de los hogares sufren inseguridad alimentaria y más del $20 \%$ de los niños menores de cinco años soportan desnutrición. 
por un bajo nivel de recaudo, una escasa recaudación de impuestos directos, un favorecimiento a las rentas de capital mediante las exenciones, poca o ninguna participación del impuesto al patrimonio, lo que en conjunto explica la debilidad estructural de sus sistemas tributarios: no se utilizan de manera significativa como instrumento redistributivo. Situación contraria sucede en los países desarrollados económicamente, donde la política fiscal ha sabido encaminarse hacia la consecución de una redistribución de la riqueza de mercado a favor de los sectores de menores ingresos.

Pese a que la situación de América Latina no se muestra como la más favorable y aún el camino a la equidad se revela bastante largo, las políticas fiscales han contribuido en la disminución de la desigualdad de ingresos en el interior de sus naciones. En países como Brasil y Costa Rica, el índice de Gini, después de impuestos, disminuye, en promedio, unos 0.013 puntos. Empero, en Colombia, donde justamente han sido más débiles los esfuerzos por promover la equidad tributaria, en comparación con la generalidad de los demás países latinoamericanos y los de ingreso medio alto, los índices de desigualdad lejos de mejorar se han mantenido en cifras preocupantes. Así, Colombia, después de aplicada la política fiscal, presenta un índice de Gini aún más alto que el manifestado antes de impuestos: este aumenta en 0.001 (Gómez \& Morán, 2013). Esto devela que la política fiscal colombiana funciona, necesariamente, como un agravante a la situación de desigualdad nacional, pues favorece abiertamente una mayor concentración de la riqueza en las clases económicamente altas y un mayor empobrecimiento de las clases de bajos recursos monetarios.

Por lo que hay que preguntar es por los fundamentos bajo los cuales se han diseñado e implementado las reformas tributarias en el país, que contienen disposiciones en cuanto a la carga tributaria, su estructura y el control de la evasión de impuestos. Quien tiene la posibilidad de establecer configuraciones en cuanto a quién, por qué y cuánto debe pagarse al Estado por concepto de impuestos, es cada uno de los gobiernos de turno que lo consigna bajo la figura de reformas tributarias. Estas, desde el lado del recaudo, pueden, por ejemplo, obedecer a objetivos como la búsqueda de un aumento en el recaudo, mayor eficiencia en su recaudación o la disminución de la inequidad.

Aquí lo esencial será reconocer que el aprovechamiento o desaprovechamiento del potencial redistributivo que lleva inmerso la política fiscal, está supeditado al choque de intereses de los diferentes grupos que conforman la sociedad. Las decisiones que lleguen a tomarse en cuanto a esta política serán un intento por recoger los resultados de la negociación entre las diversas partes. Difícilmente podría ocultarse que: "Las tarifas y bases tributarias, el monto, la dirección del gasto y la deuda pública no son el resultado de un cálculo económico puro, sino de una negociación política" (Hernández, 2005, p.70). La realidad deja ver con 
entera claridad que, aunque la política fiscal sea de carácter económico, estará antecedida por la actividad política que decide, en últimas, su curso. Justamente, bajo este reconocimiento es que deben interpretarse las reformas tributarias surgidas en el país entre los años 1990-2010.

Estas reformas devienen, según cálculos propios basados en cifras de gestión publicadas por la DIAN, en transformaciones bastante significativas en lo que al crecimiento del recaudo de impuesto de renta y de IVA respecta. Mientras para 1990 el recaudo de impuesto por concepto de renta representó el $41 \%$ y de IVAel $32 \%$ del recaudo total, veinte años más tarde estos porcentajes serían del orden del $40 \%$ y $44 \%$, respectivamente (Ver Figura 1). Esto reafirma una preponderancia significativa del IVA frente al impuesto a la renta: en términos monetarios, el recaudo de IVA aumentó 50 veces frente al de impuesto a la renta, que aumenta solamente 34 veces.

Figura 1. Participación en el recaudo total.

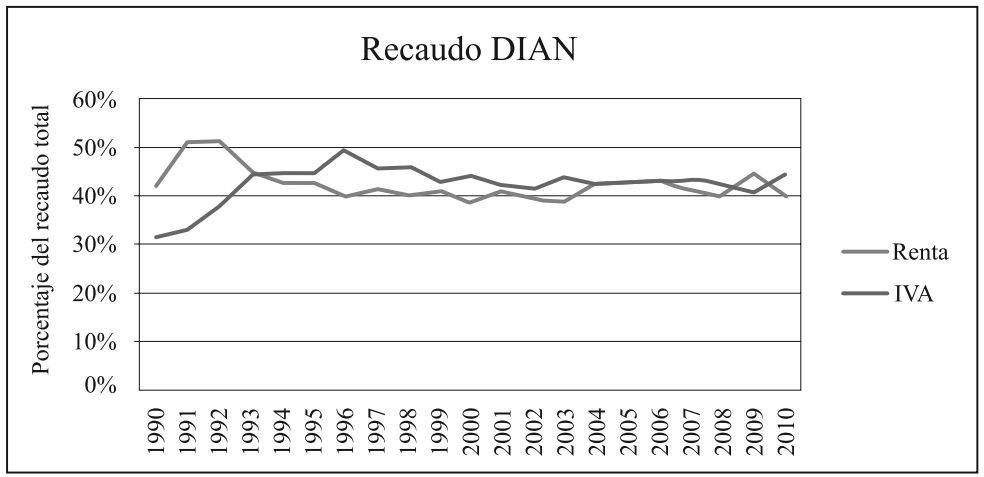

Fuente: cálculos de los autores con base en cifras de la DIAN.

Lo anterior es equivalente a decir que en Colombia la forma en que se recaudan los impuestos no ha presentado transformaciones de tipo estructural: sus ajustes han permanecido en el plano de lo netamente coyuntural que casi siempre intenta atender, aunque a corto plazo, el problema de déficit fiscal. Se tiene así un sistema impositivo caracterizado, centralmente, porque la mayor carga tributaria la asume un impuesto indirecto, el IVA, que es regresivo en Colombia e incrementa la desigualdad de ingresos en 1,2 puntos Gini (Moller, 2012); mientras que, en términos comparativos, el impuesto a la renta ha visto alivianada su carga. Significa, entonces, que los impuestos han funcionado bajo esquemas regresivos. $\mathrm{La}$ primacía en la estructura fiscal la tiene un tipo de impuesto que no diferencia según la capacidad de pago del contribuyente y sus consecuencias son apenas evidentes: 
la acentuación de la riqueza en los ricos y de la pobreza en los pobres ${ }^{3}$.

La problemática en estudio está directamente relacionada con el nivel de recaudo. Este en Colombia ha crecido conforme aumenta la base gravable, esto es, los impuestos no han visto florecer una productividad en términos de capacidad real para recaudar. En el país y para el año 2010, el recaudo fiscal total representó el $17,3 \%$ del PIB, mientras que el promedio para América Latina fue de 19,1\% y el de los países miembros de la OCDE, del 33,8 \%. Así, Colombia se encuentra significativamente por debajo del promedio alcanzado por América Latina, ya de por sí bastante inferior si se compara con el obtenido por los países de la OCDE (Gómez \& Morán, 2013). Esta incapacidad de recaudación tributaria lleva a optar por una segunda opción menos acertada: la de aumentar la base gravable mediante reformas cada uno o dos años.

La búsqueda de aumento continuo de beneficios económicos es un factor que funciona como obstáculo al positivo devenir del proceso de recaudo: "La existencia de la doble contabilidad y la presencia de especialistas tributarios muestran que los individuos y las em- presas actúan de forma consciente para minimizar sus ingresos gravables, lo cual es totalmente coherente con el principio de racionalidad económica" (García \& Gómez, 2005, p.54). Y se ha visto que esta racionalidad no se detiene ante nada: justifica todo, aun si es necesario infringir la ley, violentar las arcas del fisco y arruinar así la situación presupuestal del Estado. Se trata pues de una racionalidad que de cifras sabe mucho pero que nada conoce de fundamentos éticos y morales.

Así, el sistema impositivo colombiano ha padecido por causa de altos niveles de evasión. Como bien lo sustenta Rodríguez, O. (2001), esta evasión ha sido imposible de frenar, como resultado, en buena parte, de la oposición de organizaciones gremiales a hacer públicos sus libros de contabilidad y, en concordancia con esto, se han opuesto también a que la evasión se legisle como delito penal. De modo tal que, aunque el control de la evasión haya quedado escrito como objetivo dentro de algunas de las reformas tributarias, lo cierto es que en la realidad no se ha materializado: "La evasión del impuesto a la renta, un $27 \%$, representa unos $\$ 11,6$ billones al año, la evasión en IVA otros $\$ 8,3$ billones y por otra parte el contrabando se estima supera los 4.000

\footnotetext{
Es irrisoria la pretensión de justificar tal estado de cosas arguyendo que la focalización del gasto público revertirá la regresividad del sistema impositivo, cuando sabido es que en sumados casos los estratos de mejor condición económica terminan favorecidos del gasto estatal en educación superior, salud, pensiones, por solo nombrar algunos. En Colombia no ha sido posible impedir que el gasto público se incline hacia el favorecimiento de intereses particulares y mezquinos. Pruebas de ello, la denuncia pública que realiza el profesor Salomón Kalmanovitz, basado en un informe de la Contraloría General de la República: el Incoder, sin tener dentro de sus funciones la inversión en distritos de riego y drenaje, pero con la expedición del decreto 732 de 2008 se le permitió a Mocarí recibir dichas inversiones que privilegiaron el patrimonio de los Uribe Moreno con al menos $\$ 1.411$ millones. Ello es expresión clara de la ley colombiana: no necesariamente guarda por el derecho de todos los ciudadanos, sino que se congracia con unos intereses del poder que, en este caso, fueron los del entonces presidente de la República.
} 
millones de dólares al año" (Departamento Nacional de Planeación-DNP-, 2011, p. 784). Y quizá no se hubiese alcanzado tales cifras de no ser porque los contadores no solo se han hecho buenos en el arte de distinguir entre el debe y el haber, sino que también han sabido hacer uso de su conocimiento para alterar los balances y disminuir el monto de la obligación tributaria.

Otro agravante al bajo recaudo son las exenciones de pagos tributarios a algunos bienes o sectores que, además de valerle al Estado una pérdida millonaria de $\$ 13$ billones anuales, tendrían una consecuencia adicional: promover una cultura de "captura de rentas", en la que los demás bienes o sectores buscarán la forma de asemejarse a los que se encuentran exentos, estando incluso dispuestos a pagar por estas prebendas. En este sentido, habrá que reconocer, dentro del análisis del desarrollo de las reformas tributarias, que la presión de los grupos de poder ha tenido una influencia trascendental en la conformación de la compleja estructura tributaria del país. Lo pronunciado en la ponencia para primer debate al proyecto de ley 039 de 2006, disuelve cualquier duda que se pudiera guardar al respecto:

Fueron sentidas las intervenciones del sector agropecuario, del sector del transporte, del sector de la cultura, del sector de aerolíneas, del sector financiero, del sector de reforestación, del sector de los servicios públicos, del sector editorial, del sector de la construcción, del sector solidario, del sector de zonas francas, todos ellos reconociendo que las distintas reformas tributarias les han otorgado ciertos tratamientos bien sea por efecto de exenciones en el impuesto o desgravamen de ingresos o por otorgamiento de deducciones especiales más allá del pago normal del cien por ciento o por descuentos tributarios afectando directamente el impuesto o simplemente por manejo de tarifas diferenciales y reducidas frente al común denominador de los contribuyentes, que en la expresión manifiesta a través de dichos foros pretenden desde luego la permanencia bajo dicho esquema tributario. (Contraloría General de la República, 2012, p.17)

Para revelar la magnitud de los beneficios otorgados a los grandes dueños del capital, bastaría mencionar la Ley 1111 de 2006. Mediante esta se determina la eliminación de la sobretasa del impuesto de renta a partir del 2007, una reducción de la tarifa de renta de personas jurídicas al $34 \%$ en 2007 y al $33 \%$ en 2008, un aumento de la deducción por inversión del $30 \%$ al $40 \%$ y la eliminación del impuesto de remesas. Esto último implica que las transferencias al exterior de rentas y ganancias ocasionales percibidas en el interior del país por compañías de inversión extranjera, quedan libres de toda obligación tributaria. Y no solo eso. Cuando el crecimiento económico repercute en mayores ingresos tributarios, tal como sucedió en el 2006, la idea que ha surgido en las mentes de los hacedores de 
política fiscal en el país es la de devolver impuestos a las empresas y a los ricos

Algo podría despertar aun más asombro: en el mes de julio de 2005, los Santodomingo no se vieron obligados a pagar monto alguno por concepto de impuesto al realizar la venta de Bavaria a la compañía SABMiller, en una operación de 7.800 millones de dólares. De modo que es todo un reto la comprensión de la lógica bajo la cual opera este tipo de hechos: se le niega a un país entero la posibilidad de ver aumentados los recursos que hacen falta por doquier, mientras se privilegia de manera gigantesca a un negocio millonario.

En cuanto a las deducciones y exenciones tributarias, cabría expresar el desconcierto que estas generan, en palabras de Kalmanovitz (2009): "No conozco un país en el mundo donde una parte tan importante de la acumulación de maquinaria corra por cuenta de los contribuyentes, lo cual no es sólo inequitativo y lesiona el empleo sino ineficiente e inocuo". Si los incentivos fiscales son apoyados, la mayoría de veces bajo argumentos de promoción e incentivo a la inversión, lo cierto es que además de desviar los recursos de su asignación más eficiente, beneficia inversiones que se hubiesen realizado independientemente de la existencia o no de este alivio tributario.

En nombre de este supuesto, que no solo es incapaz de sostenerse a sí mismo sino que además permite ocultar bajo un tinte técnico el beneficio ofrecido por el Estado a unos pocos, las exenciones a los impuestos de renta llegaron a aumentar en un $50 \%$ desde el año 2000, según lo evidencia la Contraloría General. De todos modos, las exenciones son el instrumento de incentivo más inconveniente, pues en muchos casos el costo fiscal es significativamente mayor a las inversiones que en realidad logra promover (García \& Gómez, 2005). El panorama resultante de la disminución o eliminación de las exenciones sería significativamente positivo: el Estado vería aumentado su ingreso para poner en marcha procesos de redistribución de manera tal que se beneficie a quienes están en condiciones menos favorables a través de inversión en educación, salud, infraestructura, investigación y desarrollo. Medidas, por supuesto, encaminadas todas a construir un país con oportunidades laborales y sociales que cobijen al conjunto de la población.

El argumento de incentivo a la inversión vía exenciones tributarias se hace patente como mito en el estudio riguroso que de ello realiza el DNP: "La eliminación de los incentivos tributarios tiene un impacto positivo sobre el Producto Interno Bruto, especialmente en el caso del impuesto sobre la renta" (Hernández, Soto, Prada \& Ramírez, 2000, p.22). El impacto positivo de la eliminación conjunta de beneficios del IVA y de renta es múltiple: un incremento en 0,17 puntos porcentuales del PIB, una ampliación del empleo y un crecimiento de la inversión privada de $5,79 \%$, resultados a todas luces significativos.

Si de las exenciones al impuesto a la renta quienes han resultado enormemente beneficiados han sido las empresas, claro 
que después de las personas naturales, pues en Colombia estas casi no tributan, las exenciones realizadas al IVA también tienen un efecto regresivo. El economista Eduardo Sarmiento (1996) encuentra que el $10 \%$ más rico paga la mitad de lo que paga el $10 \%$ más pobre por concepto de IVA, y entonces se reconoce que el problema de inequidad es de magnitudes abismales. Esto lo sustenta contundentemente el Banco Mundial (2012) en un informe realizado para Colombia: el gasto en consumo, en términos absolutos, de alimentos gravados a tasa cero (carne, pescado, leche, queso fresco y huevos) realizado por el quintil más rico representa el $24,8 \%$ del total de los quintiles, mientras el quintil más pobre participa con el $15 \%$ del consumo.

Ha faltado, además, la suficiente voluntad política para hacer que la propiedad de la tierra, las pensiones y las herencias tributen lo suficiente como para ganar siquiera un poco de equidad en la forma como se recaudan los impuestos en el país. En cuanto al primero, el $58 \%$ del catastro de las tierras está desactualizado, lo que posibilita un pago de impuesto que poco o nada se corresponde con el verdadero valor de la obligación tributaria y que repercute directamente en las condiciones rurales: escasa financiación de servicios sociales, de seguridad e infraestructura. En cuanto al segundo, fue solo a partir de 1998 que se establecen unos límites a las exenciones de pensiones: únicamente están obligados a contribuir las pensiones que superen los \$26 millones, de modo que el monto exento es suficientemente alto. En cuanto al tercero, no ha causado interés alguno, tampoco, en los gobiernos, el incluir el pago de obligaciones fiscales a las herencias que habría podido contribuir al freno de la reproducción de los excesivos privilegios.

Las características del proceso de recaudo fiscal en Colombia son en definitiva muy particulares. El Estado colombiano no posee el monopolio fiscal, pues también imponen, por medio de la fuerza, el pago de tributos diversos, los grupos violentos al margen de la ley. El impuesto al valor agregado se convirtió en el principal instrumento de recaudo tributario en Colombia a partir de los años noventa. El $60 \%$ de las contribuciones corren por cuenta del consumidor y el porcentaje restante por cuenta de las empresas, o también de las personas jurídicas, pues los propietarios gozan de importantes beneficios, menos del $2 \%$ de la población colombiana adulta paga impuesto a la renta, y está libre de toda obligación tributaria por concepto de dividendos (Kalmanovitz, 2010). Los asalariados de ingresos altos también se ven ampliamente favorecidos mediante deducciones por ahorro en fondos de pensión. En pocas palabras, el sistema impositivo colombiano es inequitativo y existen fuerzas políticas y sociales que perpetúan esta situación.

\section{ÉTICA Y RECAUDO TRIBUTARIO COLOMBIANO}

Si líneas atrás se ha enunciado, a la elocuente voz de los hechos, el panorama de inequidad en el recaudo tributario 
colombiano, fundamentado entre otras cosas en el querer cogerle al Estado todo cuanto sea posible, ahora habrá que adentrarse en unas indagaciones que resultan apenas pertinentes. ¿Debe acaso considerarse como una normalidad que los dirigentes políticos del país jueguen a olvidar la necesidad de promover una igualdad de derechos mientras favorecen abiertamente los intereses particulares de unos pocos? ¿Debe acaso considerarse como una normalidad que la población colombiana de menores ingresos sea quien lleve a cuestas el desmesurado peso que implica el favorecer fiscalmente a unos grupos económicos opulentos? Es decir, ¿debe el colombiano acostumbrarse y acomodarse a este panorama mientras ansía para sí poder gozar de estos mismos privilegios? Pues bien es sabido, merced a la experiencia, que cuando al que se favorece es al otro se le mira con fuerte desacuerdo pero cuando el privilegiado es él mismo la cosa es enteramente contraria.

Se tiene, entonces, que no ha sido posible condicionar el sistema impositivo colombiano bajo el principio de la equidad, esto es, que quienes más tengan posibilidad de pago asuman una mayor responsabilidad con la financiación del Estado, aun siendo ampliamente conocida la pésima distribución del ingreso dentro del país. El resultado no puede ser otro que el agudizamiento de la inequidad mientras se pasa por alto el potencial del sistema impositivo en la construcción de un panorama social un tanto menos inequitativo. A todas luces se vislumbra una problemática constante y sonante pero ¿qué se dice respecto a sus más primarias causas? Se ve publicar una serie de trabajos donde se diagnostica y se describe esta situación. En el mejor de los casos, se determina claramente el panorama que bien representaría el mundo al revés: uno de los países más inequitativos del mundo hace uso del recaudo tributario de forma tal que la principal fuente de ingreso estatal son los impuestos indirectos. Y lo que perdura, en tanto, es el desconocimiento del fundamento que reproduce esta situación.

Si este panorama intenta observarse desde la lupa de la técnica que de cifras, cálculos y predicciones puede saber mucho pero que deja por fuera temas como la política, el Estado, la ética y la cultura del país, las conclusiones que se alcanzarán habrán de contribuir muy poco a la comprensión de sus más profundas raíces. Y sucede que son, justamente, estas raíces las que pueden dar cuenta de la manera en que ha venido formándose este árbol que, en los términos de la metáfora, sería el país. Ese leño, hay que decirlo, es la expresión más clara de la herencia dejada por el periodo de la colonización española cuya sombra acobija dolorosamente al país.

Así, si lo que se está intentando analizar es el recaudo tributario pero, tal y como se sabe, este remite al tema de lo estatal, habrá que iniciar reconociendo que "el problema del Estado colombiano es político antes que administrativo y técnico" (Palacios, 1995, p.350). Ello se concibe más claramente aun cuando se distingue que lo que hay detrás de toda decisión humana no es una operación ciertamente racional 
al estilo de una computadora, sino que la realidad es bastante más compleja: es la influencia de todas los cimientos éticos y culturales que arraigados de manera casi radical en el interior de aquel hombre, que actúa como político, funcionario, empresario y ciudadano, establece una forma de relacionarse consigo mismo y con el mundo del que además hace parte.

Siendo así las cosas y teniendo la pretensión de ilustrar el tema de la inequidad en el recaudo tributario nacional desde las tonalidades de la ética bajo la cual gravita el país, necesariamente deberá adentrarse de manera previa en el concepto fundamental de lo ético para, paso siguiente, hallar un acercamiento más analítico a los determinantes históricos que enraizarían una particular ética e influenciarían fuertemente el curso tomado por el país. Y finalmente, reconocer que el entorpecimiento fiscal del país protagonizado por unas capas sociales de poder no es una historia nueva, todo lo contrario, se ha hecho patente a lo largo y ancho del devenir del país. De ahí que el repensar histórico tenga la capacidad de iluminar la comprensión del panorama de estas dos décadas.

De antemano hay que mencionar que los límites de extensión del presente artículo impiden un tratamiento más minucioso de la interpretación de lo ético; no obstante, se tiene la pretensión de intentar abarcar en breves líneas lo esencial. Por ética entiéndase el temple de ánimo que impulsa al hombre a relacionarse con el mundo y con él mismo. Al existir humano, que es en cada caso el mío, el filósofo más importante del siglo XX, Martin Heidegger, lo denominaría Dasein: ese ser-ahí, que es el hombre y, que tiene la particularidad de ser el único ente que entre los demás entes tiene la posibilidad de comprender su propio ser y asimismo de hacer comprensible el mundo. Ello implica, fundamentalmente, que el hombre es posibilidad pero posibilidad en el tiempo pues es necesariamente un ir hacia la muerte. El hombre no es el señor de lo ente sino el pastor del ser (Heidegger, 2006). El hombre que ha comprendido su poder-ser hace gala a su propia condición, se relaciona con él y con el mundo a la luz de su majestuosidad: el pensar, y nada tiene que saber de mandamientos morales prefijados que guíen su conducta.

Empero, el devenir del pensamiento de Occidente ha implementado una ética que, lejos de estar fundamentada en el ser-ahí del hombre, se ha dado a la tarea de construir todo un orden teórico y práctico bajo el cual debiera dirigirse el hombre cuya máxima expresión es el más absoluto olvido del ser. En este sentido, la proposición de la ética cristiana es esencialmente distinta a la analítica heideggeriana del Dasein. En la primera, la verdad del hombre está fundamentada en otro ente que no es él mismo, esto es, en Dios. Mientras que en la segunda, la verdad del hombre emerge de su propio ser en tanto le corresponde un poder-ser comprensor de sí mismo.

El hombre se encontró a sí mismo como lo más lejano y, lejos de tenerse en su 
ser-propio, se comprendió bajo la forma de un cristiano que debiendo hallar el perdón de Dios había de interiorizar los preceptos de la Iglesia católica. Fue con la Reforma de Martín Lutero que este panorama se tornaría sustancialmente diferente: se reforma la manera de enseñar la palabra de Dios. El sentido perseguido por el hombre, la trascendencia, continuó siendo el mismo pero ahora eran otros los medios para alcanzarla. No por otra razón Max Weber puede referirse a una "ética protestante", es decir, a unos preceptos religiosos que se instauran e interiorizan a la luz del protestantismo y que impulsarían de manera trascendental el surgimiento del espíritu capitalista. El análisis de Max Weber (2012) sugiere, entonces, una mayor profundidad en la perspectiva desde la cual se abarca el suceder histórico: la comprensión de la ética, es decir, de la interiorización de determinados valores, construye un campo de interpretación de elevada profundidad.

Esto se hace patente de manera espléndida cuando se reconoce el abismo abierto entre los países alineados al protestantismo y los que, a partir de la ejecución de un proceso de contrarreforma, se afianzarían más aún a las determinaciones de la Iglesia católica. Aunque ambos fundamentarían la verdad del hombre a partir de una misma metafísica: la idea de Dios, el protestantismo impulsaría un ethos del trabajo, mientras el catolicismo continuaría despreciando el mundo de lo fáctico por ser el del pecado. Y eso no es todo: dicha forma de relacionarse se traduciría en una herencia dejada a los países colonizados y marcaría, entonces, el posterior desarrollo o estancamiento de estas repúblicas. Si el acontecer actual se mira desde esta perspectiva, es claro que el enriquecimiento, en términos de comprensión, es significativamente mayor.

Bajo este esquema, donde España hace las veces de padre y Colombia de hijo, la herencia española proyecta su reflejo al conjunto de la sociedad colombiana. Desde el pasado colonial y hasta los días presentes, los valores que guiaban el actuar del español han determinado, en consecuencia, y de manera trascendental el actuar colombiano. Ahora habrá que reconocer el trasfondo histórico sobre el cual se sentaron las bases de los valores espirituales españoles. Estos asumirían la forma de fundamento, conforme el cual interpretaría y procedería el español ante su estar en el mundo. En el pasado de los españoles existe una particularidad bastante diciente: ejecutaron una empresa histórica de defensa del cristianismo.

El fundamento que permite interpretar de manera medular la estructura del espíritu español es claro: su intenso sentimiento religioso. No hubo, pues, otro cristiano occidental que, como el español, practicara el fanatismo religioso a tal magnitud que lo viera convertido en el determinante total de sus formas de vida. Es decir, todo lo español estaba impregnado, necesariamente, de ese intenso sentimiento religioso. Y, entonces, hablar de España y del cristianismo era casi como estarse refiriendo a un mismo término. El español se autoidentificaba como caballero 
cristiano, donde se apreciaba a sí mismo en tanto héroe. Y héroe en el sentido de defensor a sangre y fuego de su propia verdad, esto es, de la idea de Dios. Siente, pues, que su misión es heroica: destruir a los no creyentes. Acá se hace patente, de manera esencial, una relación amigo-enemigo: se ha de atacar a todo el que se oponga a interiorizar el dogma católico. Apenas resulta lógico deducir que actuaban bajo el precepto: ¡quien no está conmigo, está contra mí! Creyendo el español, además, estar llamado por la divinidad para expandir e impartir fervorosamente el catolicismo, se sentía por este mismo motivo digno de la más altas estimaciones y honores.

La nobleza española, adherida absolutamente a los principios de la Iglesia católica, apeló como carente de valor el surgimiento del homo economicus. Si las características centrales del hombre protestante fueron la disposición para el trabajo, la austeridad en el consumo y la previsión del futuro, el español sentía desprecio por todas ellas. Eran los títulos decorosos y la posesión de tierras los únicos intereses terrenales que parecía manifestar el español. El curso de la historia deparaba grandes cambios: el descubrimiento de América. Frente a los ojos de los españoles lo que se presentaba era nada más y nada menos que una empresa de carácter militar y religioso. Exigía entonces del español ese espíritu ya de por sí innato de heroicidad y grandeza. Por lo demás, abría las puertas de par en par para que sin notable esfuerzo dispusiese de riquezas y de población de la cual absorber fuerza de trabajo (Jarami1lo, 1964). Acá se veían cumplidas las más profundas aspiraciones de los españoles llegados a América: aparentar e igualar la elevada posición social de los españoles de la Corona sin tener que incurrir en la penosa tarea de trabajar.

Si en España las clases que tenían un mayor poder eran la burocracia, el servicio eclesiástico y el militar, todas ellas improductivas, con su llegada al continente lo que tuvo lugar fue una trasmisión y reproducción idéntica de estas formas. Este trío de oficios tenía sentido a la luz del misticismo religioso y, más allá de eso, de nada quería saber. Era, pues, el pálpito y no el cálculo el sentido sobre el cual se conducía el español. Américo Castro (citado por Jaramillo, 1964) dibuja esta situación con precisión: "El caballero español, necesitaba rodearse de un halo de trascendencia, de un prestigio religioso, regio o de honra. Tenía que sentirse en un más allá mágico, y como en vilo sobre la haz de la tierra" (p. 16). Ese carácter de divinidad, esto es, el concebir todo como un perfecto designio de Dios, con el que interpretaban la realidad, sería el único que suscitaría su actuar en el mundo.

El fundamento religioso de su existir fomentó y construyó en su interior un desapego a todo lo meramente mundano. Si lo que tenía interés para el español eran el alcanzar títulos suficientes para llenarse de un goce basado en el orgullo y la vanidad que nace del reconocimiento y de una posición social, es apenas comprensible que anduviera sin el más mínimo 
cuidado de construir en el territorio, que hoy es Colombia, una administración fuerte con amplio sentido de visión futura. Siendo así las cosas, en la colonización fue imposible la construcción de bases consistentes para la formación de una sana política donde la reglamentación y el orden se irrigaran desde los dirigentes políticos hasta el conjunto de la sociedad.

Los más importantes empleos públicos estaban en manos de españoles europeos que, además de no estar radicados en Colombia, tenían plena conciencia de su papel de conquistador y un fuerte desprecio por los indígenas, mestizos e incluso por los criollos y, en consecuencia, exigían radicalmente que la Corona española les favoreciera con importantes privilegios: tierras, cargos burocráticos y títulos nobiliarios (Jaramillo, 1965). Esto no pudo traducirse más que en un panorama: ausencia de todo patriotismo y moralidad en los administradores políticos de la nación y un lamentable avasallamiento de los administrados que se ven desposeídos de medios para reflexionar e interiorizar esta situación como una problemática que les atañe directamente. $\mathrm{O}$, lo equivalente a decir: un legado de escombros del cual nada bueno parecía poder brotar.

Esperar del español acciones basadas en un espíritu calculador y planificador, una visión democrática de la política y un sentido de racionalidad económica, parece a todas luces una simple y vana ilusión. La realidad era que los valores legados por la colonización española no daban paso a la creación de una sociedad civilizada. Con clases dirigentes incapaces de gobernar, con la perversión de la empleomanía, el rechazo por las formas de trabajo y el hábito de esperarlo todo del Estado, como si de un padre omnipresente lleno de misericordia se tratara, se aislaba la posibilidad de que el colombiano interiorizara una forma de conducta enmarcada bajo los principios de orden, respeto a la ley y sentido crítico.

El afán de los gobernantes españoles de figurar y representar una posición social, no estaba fundamentado en su capacidad de liderar políticamente la construcción de una sociedad con un sistema judicial, social y económico capaz de encaminar a la nación hacia la superación del subdesarrollo, es decir, estaba basado en el valor que se quiera excepto en el de la responsabilidad. Para desgracia nuestra, la figuración que alcanzaba el dirigente político español no estaba sustentado más que en su color de piel y su linaje español. Esta no es una característica cualquiera, sus repercusiones son de magnitud descomunal. Para decirlo utilizando el término de uno de los intelectuales colombianos con mayor reconocimiento internacional, el profesor Rafael Gutiérrez Girardot (1989), este país tiene la herencia española de la simulación que permea todos y cada uno de los ámbitos de la vida colombiana. En este mismo sentido, el subdesarrollo del país ha sido:

(...) producto histórico del catolicismo de la Contrarreforma, del "misoneísmo" eclesial, del temor del dogma a ser puesto en tela de 
juicio por los saberes modernos y por la razón. El mismo poder de la Iglesia que cerró las puertas de los países hispánicos a la marcha de la historia, que los encerró en una larga noche de dogmatismo y primitivización del pensamiento, debilitó las Instituciones estatales y fomentó esa especie de irresponsabilidad civil que pintorescamente se le llama y se le celebra como picaresca hispánica. (p.276-277)

Esta picaresca se manifiesta de manera extendida en la relación que el individuo asume para con el Estado. El político, el oligarca, el burgués, dada justamente esa irresponsabilidad civil, no ha categorizado al Estado como un ente garantizador de unos derechos ciudadanos comunes que propendan a la convivencia pacífica sino que lo han visto como un botín capaz de proporcionarles a ellos, de manera exclusiva, unos privilegios económicos de amplias magnitudes. La propiedad pública pierde su categoría de servir a fines sociales y pasa a ser algo que puede ser saqueado. Acá cabría preguntar con no poca indignación: “¿Qué es lo que hace que un grupo de familias sienta que puede cogerle libremente a los demás y en particular al Estado lo que no se ha ganado?" (Kalmanovitz, 1989, p.58).

En concordancia, si algo ha sido estático en el devenir histórico del país es, justamente, la forma individual de relacionarse con el mundo a partir de la irresponsabilidad que se vio agudizar con la inexistencia de un control estatal que instaurara pautas de comportamiento basadas en el respeto, responsabilidad y conciencia. Esto significa un actuar gravitando en la in-esencialidad. Y, entonces, la situación es bastante compleja: se tiene una mezcla de despotismo centralista y unos ciudadanos que buscan afanosamente incumplir la ley por medio de engaños y picardía (Kalmanovitz, 1997). Las manifestaciones de esta ética de la irresponsabilidad se encuentran por doquier: el estudiante universitario tiende a resistirse a experimentar una relación profunda y esencial con el conocimiento, el profesor tiende cuando mucho a repetir en sus clases a modo de credo unas líneas teóricas desprovistas de todo contexto, $\mathrm{y}$ los más diversos funcionarios públicos, políticos y trabajadores quieren todo menos desempeñar un trabajo honesto y comprometido.

Esta relación con el mundo y consigo mismo a partir de la irresponsabilidad tiene su raíz en la anomia (Gutiérrez, 2005), y entiéndase por esta la desviación o ruptura del sistema de normas y valores sociales de modo que los individuos miembros de la sociedad quedan divagando en la confusión y desorientación. Ello, en últimas, explica que el individuo pueda desarrollar actitudes que van en detrimento de otros y que obstaculiza por completo la construcción de un país que sobresalga por estar enmarcado bajo un sistema político democrático propiamente dicho. En oposición, el panorama es sombrío. Cada hombre, en tanto desprovisto de toda interiorización de parámetros sociales que guíe su actuar, queda abierto 
a la posibilidad de caer preso en la red de la corrupción, la violencia, el irrespeto y, desde luego, la irresponsabilidad civil.

Esa pauta de comportamiento, el de la irresponsabilidad civil con todas sus repercusiones, lejos de superarse, tomó la forma de un viejo hábito de conducta que se resiste a la disolución. El devenir del país ha hecho patente, precisamente, formas de agudización de esa descomposición de los valores sociales: dos de los más importantes, el frente nacional y el surgimiento del narcotráfico. El primero desata el fenómeno del clientelismo y el reconocimiento de que el Estado representa a una minoría mientras deja de lado a grandes sectores sociales. El segundo trae la tentación del dinero fácil que haría de las suyas: el Estado se mezcla con la ilegalidad, proliferan los asesinos a sueldo y se instaura una cultura mafiosa.

El abuso del poder, la resistencia de los más acomodados a tributar, el favorecimiento del Estado para con las rentas de capital acompañado del menoscabo de la población de menores ingresos por el aumento del impuesto a las ventas, han sido, en conjunto, características del sistema impositivo colombiano. Ahora, sucede que esas características no se han hecho patentes únicamente a lo largo de las dos décadas que se intentan estudiar en la presente investigación, más bien han sido una constante a lo largo de la historia del país. Bajo este contexto, podría decirse que el panorama ha sido persistente: inequidad en la forma en que se recaudan los impuestos nacionales a pesar de que sus manifestaciones hayan podido sufrir ciertas variaciones a lo largo de los años. Dada la persistencia de la problemática es que parece factible interpretar la inequidad tributaria colombiana a la luz de los condicionantes éticos arraigados en el país desde el proceso de colonización. Así, al país continuar gravitando bajo los fundamentos legados por la conquista española, la situación, lejos de encontrar la vía a su superación, se ha reproducido una y otra vez.

$\mathrm{Ni}$ en el pasado ni en el presente se ha conseguido, entonces, que los ricos y poderosos paguen impuestos según su capacidad monetaria. Si lo que existe es una forma de relacionarse con los impuestos desde el fraude, la evasión, la elusión, la compra de favorecimiento de unos intereses particulares, donde, además "el propio régimen jurídico les sanciona su derecho a evadir impuestos, porque lo clasifica como una contravención y no como un delito a la propiedad, en este caso la pública" (Kalmanovitz, 1991, p. 321), de modo que el Estado es flexible ante esa situación, es claro que el principio de equidad no puede ni siquiera, en el mejor de los casos, figurar en el papel. Sectores económicos como el ganadero, agrícola, cafetero, petrolero, han sabido desvincularse en cierta media del sistema impositivo por medio del favorecimiento político del que su posición económica les permite gozar a sus anchas. Empero, la mayoría de colombianos no pueden osarse de esas mismas gracias. La población de pequeños y medianos ingresos, contrario 
a los adinerados, no puede eludir sus cargas tributarias buscando socios en el Congreso ni aparentando unas cifras contables que nada tienen que ver con la realidad, sino que llevan a cuestas la imposición de pagos por concepto de IVA con el que se sostienen, principalmente, las finanzas fiscales del país.

Y, entonces, tal y como lo expresa Marco Palacios (1995): "El talón de Aquiles económico del Estado colombiano parece residir en su baja capacidad fiscal extractiva" (p. 248). Ello lo que pone de manifiesto es nada más y nada menos la debilidad del Estado que, por lo demás, ha sido histórica. Es la debilidad de un Estado que no ha tenido la voluntad de asumirse esencialmente, esto es, reconocerse como lo que es, un ente que tiene a su encargo la garantía de unos derechos comunes a todos los habitantes. El panorama no es, en modo alguno, alentador: su debilidad se hace patente de manera trascendental en la inequidad bajo la cual gravita el sistema impositivo colombiano. El Estado es incapaz de impedir su sometimiento bajo grupos de poder que terminan coaptando el Estado para su beneficio propio, por supuesto, en detrimento de la gran mayoría. El Estado es entonces un ente susceptible de raptarse, corromperse, robarse, en una palabra, perderse.

Uno de los grandes del pensamiento, Nietzsche, vendría a decir: "el hombre es un animal no fijado". Cada hombre en el devenir propio de su vida decide todas y cada una de sus actuaciones movido bajo la interiorización de unos principios. Estos principios pueden conducirlo hacia una vida vigorosa caracterizada por la esencialidad o marchita en la in-esencialidad. En el caso del hombre colombiano, la interiorización del dogmatismo católico legado por el español permea cada uno de los ámbitos de la esfera social y dirige su actuar a partir del principio de la irresponsabilidad. El resultado es, entonces, una sociedad que sobresale por la hostilidad, la trampa, el engaño, el egoísmo, en resumen, por el caos.

Si el hombre, que es en cada caso él mismo, está llamado a asumir su mismidad, esto es, a comprender su poder-ser, a pensar, la metafísica judeocristiana no se sigue cuestionando por el ser, pues la verdad es Dios, el ente creador del cosmos y la criatura, capaz de responder todas y cada una de las inquietudes que ronda en el espíritu del hombre. El hombre está inmerso, entonces, en el camino de alcanzar la redención de sus culpas y la salvación de su alma otorgada por la gracia de Dios. Si el hombre tiene una meta, alcanzar el más allá, el mundo fáctico le resulta despreciable por ser, justamente, el espacio del pecado. El español interiorizó de manera intensa esta metafísica y la hereda a la actual Colombia. Ello es trascendental: se coarta la posibilidad de pensar su mismidad y se traduce, además, en una ética de la irresponsabilidad y la arbitrariedad. De ahí que el peso del legado español sea de tan considerable magnitud para Colombia. 


\section{CONCLUSIONES}

El Estado es constitutivamente conflictivo y la cuestión del sistema impositivo en cuanto atañe al accionar estatal queda condicionada a las complejidades propias del Estado. Son los impuestos, entonces, el punto donde se pone de manifiesto el cruce de intereses de los más diversos sectores sociales. Sucede, el fundamento del Estado son los impuestos, es decir, desposeído del monopolio fiscal su capacidad de sostenerse ciertamente se desvanecería. Los ciudadanos, entonces, financian el sostenimiento de un Estado que les compensará con civilización y que, al mismo tiempo, deberá pretender el bienestar colectivo que defienda los intereses de los más débiles. El principio de equidad tributaria debe, entonces, figurar como prioridad en la política económica.

Para el caso colombiano, el Estado no ha interiorizado el compromiso que expresa mediante la Constitución en lo que a este principio respecta. Sus diversos gobiernos de turno han favorecido abiertamente a unas minorías vía impuestos bajo una multiplicidad de medidas: reducción por inversión en activos fijos, rentas exentas, descuentos tributarios, precario control de la evasión por oposición de ciertos grupos económicos, exenciones al IVA que favorecen a los más adinerados y poca tributación de la propiedad de la tierra. Ello desemboca irremediablemente en pérdidas millonarias para el Estado que deben solucionarse de alguna manera: aumentando la tasa y la base gravable del IVA, justamente, por su facilidad de recaudo. De manera que lo que prima es el concepto de eficiencia y de un supuesto incentivo a la inversión cuando ambos argumentos son sumamente discutibles y caen por su propio peso. Es la historia de un Estado que sirve a unos pocos en detrimento de la enorme mayoría. De modo tal, la razón de que el sistema impositivo colombiano sea de carácter regresivo, esto es, que hace más ricos a los ricos y más pobres a los pobres, no está asociada a un problema de tipo administrativo o técnico sino político.

Si se tiene la intención de comprender lo que guarda, en términos esenciales, esta problemática de inequidad en el recaudo colombiano, habrá que visualizar su trasfondo: puede decirse que tiene por causa primera, fundamentalmente, no unas fallas en el ámbito de lo técnico-operativo, sino que es manifestación de una ética de la irresponsabilidad, hija del dogmatismo católico impregnado en la sociedad colombiana desde el proceso de conquista. Lo que hay detrás, es, sin duda, toda una complejidad social en medio de la cual tiene lugar el devenir del país y que sigue determinando la historia que se escribe de este. La interiorización de pautas de comportamiento basadas en el truco, la mentirilla, el desprecio por el trabajo, el querer ostentar de una posición social, la relación siervo-esclavo, el provincianismo y, más fundamentalmente, la irresponsabilidad civil, han dejado dolientes manifestaciones a lo largo y ancho del trajinado pasado y presente colombiano. La clase política está en función de todo menos de propender a la búsqueda del bienestar colectivo, los grupos 
económicos de mayor poder ven al Estado como un benefactor de sus intereses egoístas, se extiende la visión de esperarlo todo del Estado y la inmensa mayoría tiene que ver cómo el Estado minimiza sus derechos para ampliar los de unos pocos.

Ante la problemática en cuestión, lo que quedaría por hacer es recobrar la mirada crítica como la única manera de comprender tal estado de cosas. Reconocer que la problemática es fundamentalmente de carácter ético, esto es, de un temple de ánimo que embargado por la irresponsabilidad ha llevado al colombiano a relacionarse de tan precaria manera con el mundo y con él mismo. Si no se renunciara al pensamiento y a la responsabilidad, el país decididamente sería otro: uno donde la expresión del pacto social sea la justicia y la equidad, uno donde sea el discurso y no la arbitrariedad el que decida el curso del país, uno donde quienes más tengan más tributen sin importar sus influencias políticas y económicas, uno donde no se relegue a una función macroeconómica la tarea de contribuir a la disminución de la inequidad en la distribución del ingreso que se sabe debe nacer de una voluntad política, es decir, de un Estado fuerte, democrático propiamente dicho que promoviendo la responsabilidad pública pueda ganar legitimidad. Todo ello implica sumergirse de manera profunda en la comprensión del hombre y de la sociedad, rechazando el dogma y abrazando la majestuosidad del pensamiento.

\section{REFERENCIAS}

Arévalo, D. \& Rodríguez, S. (2001). Gremios, reformas tributarias y administración de impuestos en Colombia. Bogotá: Universidad Externado de Colombia.

Banco Mundial. (2012). El gasto tributario en Colombia: una propuesta de evaluación integral y sistémica de este instrumento de política pública. Bogotá: s.n.

Contraloría General de la República. (2012). Comentario de la Contraloría General de la República al proyecto de ley no. 166/2012 c, 134/12 s, "por la cual se expiden normas en materia tributaria y se dictan otras disposiciones". Bogotá.

Departamento Nacional de Planeación-DNP- (2011). Plan nacional de desarrollo 2010-2014. Tomo II. Bogotá: DNP.

García, M. \& Gómez, A. P. (2005). ¿Han aumentado el recaudo las reformas tributarias en Colombia? Revista de economía institucional, 7(12), 43-61.

Gómez, J. \& Morán, D. (2013). Política tributaria en América Latina: agenda para una segunda generación de reformas. Santiago de Chile: CEPAL.

Gutiérrez, R. (1989). Hispanoamérica: imágenes y perspectivas. Bogotá: Temis. 
Gutiérrez, R. (2005). Estratificación social, cultura y violencia en Colombia. Revista Aquelarre, $4(8)$.

Heidegger, M. (2006). ¿Qué es metafísica? Madrid: Alianza.

Hernández, Soto, Prada \& Ramírez. (2000). Exenciones tributarias: costo fiscal y análisis de incidencia. Bogotá: Archivos de macroeconomía, Departamento Nacional de Planeación.

Hernández, I. (2005). Teoría política fiscal. Bogotá: Universidad Externado de Colombia.

Hobbes, T. (1994). Leviatán: la materia, la forma y poder de un Estado eclesiástico y civil. Barcelona: Altaya.

Jaramillo, J. (1964). El pensamiento económico en el siglo XIX. Bogotá: Temis.

Jaramillo, J. (1965). Mestizaje y diferenciación social en el Nuevo Reino de Granada en la segunda mitad del siglo XVIII. En Anuario colombiano de historia social y de la cultura, 3 (pp. 21-41). Bogotá: Banco de la República.

Kalmanovitz, S. (1989). La encrucijada de la sinrazón y otros ensayos. Bogotá: Tercer Mundo.

Kalmanovitz, S. (1991). Modernidad y competencia. En F. Viviescas \& F. Giraldo. (Comps.). Colombia: el despertar de la modernidad (pp.311-325). Bogotá: Foro Nacional por Colombia.

Kalmanovitz, S. (1997). Las instituciones, la ley y el desarrollo económico. En Borradores semanales de economía $N^{\circ}$ 69. Bogotá: Banco de la República.

Kalmanovitz, S. (2009, 19 de julio). De tributos justos. El Espectador. Recuperado de http:// www.elespectador.com/columna151518-de-tributos-justos

Kalmanovitz, S. (2010). Nueva historia económica de Colombia. Bogotá: Taurus.

Keynes, J. M. (1943). Teoría general del interés, la ocupación y el dinero. México: Fondo de Cultura Económica.

Mann, M. (1997). Las fuentes del poder social. Cinco teorías del Estado. Madrid: Alianza.

Moller, L. C. (2012). Politica fiscal en Colombia: aprovechamiento de su potencial para lograr una sociedad más equitativa. Bogotá: Banco Mundial.

Palacios, M. (1995). Entre la legitimidad y la violencia: Colombia 1875-1994. Bogotá: Norma.

Petty, W. (1986). The Economic Writing. A Treatise of Taxes and Contributions. New York: Augustus M. Kelley Publishers.

Rodríguez, O. (2001). Gremios, reformas tributarias y administración de impuestos en Colombia. Bogotá: Universidad Externado de Colombia. 
Sarmiento, E. (1996). Apertura y crecimiento económico: de la ilusión al nuevo estado. Bogotá: Tercer Mundo.

Weber, M. (2012). La ética protestante y el espiritu del capitalismo. Madrid: Alianza. 